\title{
GCU
}

Glasgow Caledonian

University

University for the Common Good

\section{Multiple perspectives on blended learning design}

Collis, Betty; Margaryan, Anoush; Amory, Marc

Published in:

Journal of Learning Design

Publication date:

2005

Document Version

Publisher's PDF, also known as Version of record

Link to publication in ResearchOnline

Citation for published version (Harvard):

Collis, B, Margaryan, A \& Amory, M 2005, 'Multiple perspectives on blended learning design', Journal of Learning Design, vol. 1, no. 1, pp. 12-21. <http://researchonline.gcu.ac.uk/edu/21>

\section{General rights}

Copyright and moral rights for the publications made accessible in the public portal are retained by the authors and/or other copyright owners and it is a condition of accessing publications that users recognise and abide by the legal requirements associated with these rights.

Take down policy

If you believe that this document breaches copyright please view our takedown policy at https://edshare.gcu.ac.uk/id/eprint/5179 for details of how to contact us. 


\title{
MULTIPLE PERSPECTIVES ON BLENDED LEARNING DESIGN
}

\author{
Betty Collis \& Anoush Margaryan \\ Faculty of Behavioural Science \\ University of Twente, THE NETHERLANDS \\ Betty.Collis@Utwente.nl,a.margaryan@utwente.nl \\ Marc Amory \\ Learning \& Leadership Development \\ Shell International Exploration \& Production, THE NETHERLANDS \\ Marc.Amory@Shell.com
}

\begin{abstract}
Learning in the corporate setting not only relates to individual competence development but also to a demonstration of business impact and a contribution to the strategic ambitions of the company. An approach to learning design that blends generic principles of learning and instruction with strategic goals important to the particular context, anchored in a commitment to authentic and engaging learning activities is needed. We describe how a particular action-research partnership has developed such an approach to learning design, give examples of learning events that illustrate the design, and then synthesize results of 12 of these events from three perspectives-the designer/researcher, the instructor, and the participant--in order to reflect on the lessons learned and apply them in an on-going way to a dynamic learning evolution. Although the experiences reported are from one global corporate setting, the research-based reference model used to steer this approach to learning design is by its very nature adaptable to other organizational contexts.
\end{abstract}

Keywords

Work-based learning, blended learning, corporate learning, learning design, Action Research, first principles of instruction

\section{Learning Design for the Corporate Setting}

Learning in the corporate setting not only relates to individual competence development but also to a demonstration of business impact and a contribution to the strategic ambitions of the company. An approach to learning design that blends generic principles of learning and instruction with strategic goals important to the particular context, anchored in a commitment to authentic and engaging learning activities is needed. We discuss a generic reference model for such an approach in this section.

\section{Learning in the Corporate Context}

Modern, global corporate workplaces are being transformed by increasing complexity, rapid changes in technology and workforce demographics, and global competition. This is particularly so for multi-national corporations with highly skilled technical professionals such as in the oil industry. Because of the rapid changes in business processes and technologies, many organisations are facing widening competence gaps in their employees. However, learning is more than closing gaps. It calls for outcomes that demonstrate direct relevance to business needs (both short- and long-term organizational goals), as well as strengthens the capacity to respond to complex 
workplace problems by creating and sharing knowledge, collaboration and teamwork, and learning from the collective experience in the company (Margaryan \& Collis, 2004). Learning in this context arises from active participation in practice and is a product of interaction between the individual learner and the social partners (peers in the course, colleagues, workplace experts, coach, supervisor) as well as the social context in which knowledge is developed and used. Such learning has to be situated in the context of realistic business settings, where learners are not distanced from the workplace during learning but in contrast learn by solving real-world problems and interacting with the tools, people, and other resources available in the workplace (Raelin, 1998). A key in this approach is the design of courses around a blend of work-based activities in the workplace context within the structure and stimulation of peer-to-peer learning guided by an expert instructor. Such a design approach needs a reference model.

\section{A Reference Model for Learning Design in the Corporate Context}

A reference model is an abstract description of a system whose entities are described in terms of their main characteristics and where the relationship among the entities is loosely defined. In terms of learning design for the corporate context, we see a reference model as indicating key components of the type of learning approach we have described in the previous section that should be reflected in the outcomes of the design process. Such a socio-technical system is the interaction of people, the environment, technology, and work practice (Goodrum, Dorsey, \& Schwen, 1993), integrated within generic principles of instruction.

In terms of generic principles of instruction for adult professionals, Merrill has done the instructional-design community a great service by synthesizing "five first principles of instruction" out of a large collection of instructional-design theories, textbooks, articles, and perspectives (Merrill, 2002). Merrill defines first principles as "necessary for effective and efficient instruction...Learning from a given program will be promoted in direct proportion to its implementation of first principles" (p. 44). The first principles, along with minor re-expressions for corporate settings given in parentheses, are that "learning is promoted when:

1. Learners are engaged in solving real-world [i.e., business-relevant] problems.

2. Existing knowledge [in the learner or in his or her workplace] is activated as a foundation for new knowledge.

3. New knowledge is demonstrated to the learner [through seeing it in action in the workplace].

4. New knowledge is applied by the learner [to his or her current workplace situation].

5. New knowledge in integrated into the learner's world [workplace]." (Merrill, 2002, pp. 4445 , augmented with comments relating to the corporate context)

Thus the first principles are the core of the reference model. However, while the first principles are generic in terms of design, they do not express specific learning strategies for carrying out the principles in a particular corporate setting. To augment the first principles so that the needs of a particular corporate context are reflected in the learning design that is used, we suggest augmenting the generic first principles with a set of strategic principles that reflect the particular context. Together, we see these two sets of entities, the first principles and a set of strategic local principles, as forming a reference model for the design of blended learning in the corporate context. We call such a reference model the First Principles Plus model (Collis \& Margaryan, 2005). Figure 1 shows this model. 


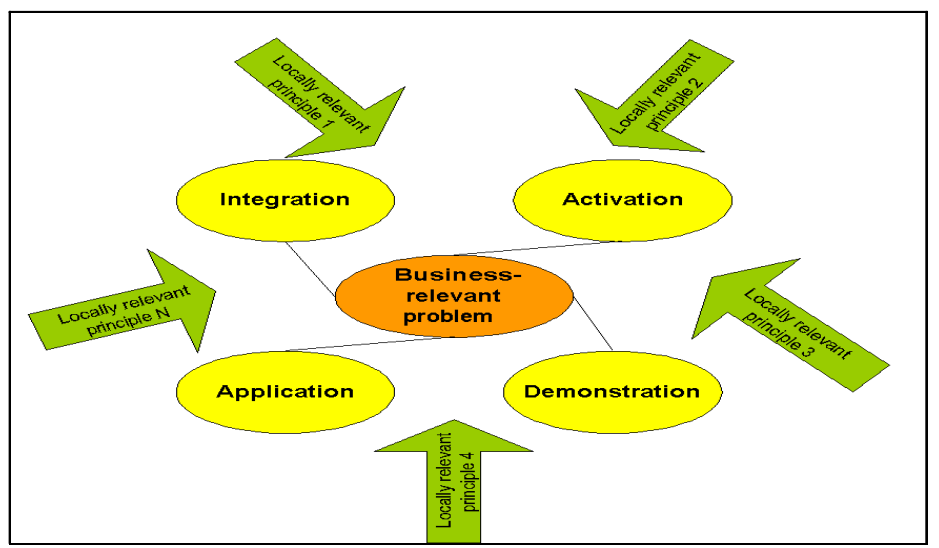

Figure 1. "First Principles Plus" reference model for learning design in the corporate setting, consisting of Merrill's five first principles of instruction (2002) augmented by some number of locally relevant strategic entities

The reference model is used in a variety of ways. It can steer design decisions, it can serve as the basis for a course-scan procedure that produces a "First Principles Plus" score per course that can contribute to reflection on course design at the individual and across-course levels, it can be used to structure and interpret formative and end-of-course evaluations, and it can serve as a strategic tool in discussions of new directions in course development (Margaryan, 2005b). To apply the reference model in practice requires an action-research approach for determining and dynamically revising the locally relevant strategic entities. Action Research involves iterative cycles of "a spiral process of planning which involves reconnaissance; taking actions; and fact-finding about the results of the action" (SFCEL, 2005), as well as applying the insights back into practice. In terms of the reference model, an action research involves first identifying the set of strategic local principles (which will be an iterative process in itself), then to apply the integrated set of principles in redesigned learning events, then to evaluate and reflect process from the perspectives of instructors, participants, and other stakeholders, and then to further refine the local strategic entities or focus on how to better put them into action in subsequent events. To illustrate this for a specific context, we next move to the case of blended learning in Shell Exploration and Production.

\section{Blended Learning at Shell EP}

The Shell Exploration and Production (Shell EP) business activities include exploring, assessing, and producing hydrocarbon reserves. ${ }^{1}$ The Shell EP business has interests in exploration and production ventures in around 36 countries and employs over 25,000 people. The technical professionals in Shell EP are predominately university graduates who represent the areas of wells engineering, field engineering, production engineering, petroleum engineering, and geosciences disciplines. Two major problems facing the oil industry are the rapidly changing developments in oil-production technology, and the "big crew change" that is occurring as senior technical professionals, typically from the UK, The Netherlands, and the USA, are retiring and being replaced by new professionals from the Middle East, Malaysia, Nigeria, and other non-western countries. In this section we identify the form of blended learning that has evolved to meet these challenges, the way the local strategies of the First Principles Plus reference model have been formulated to steer this learning design, and the results of a multi-player reflection on 12 of the blended courses.

\footnotetext{
${ }^{1}$ http://www.shell.com/home/Framework?siteId=eandp-en
} 


\section{The Reference Model for Blended Learning at Shell EP}

To deal with their two key problems, a form of blended learning focused on courses with workbased activities has been evolving at Shell EP since 2001. From the instructor's view, this approach can be seen as a ladder. At the base are core technical reference materials. The next step brings in additional resources for learning. The step that follows is often the last in traditional training: the participant is directed to carry out some exercises or in-class activities. With the Shell EP approach, another two steps are added. For the fourth step, learning-related activities are carried out in the workplace with the support of a coach or other learning facilitator. For this step, participant submissions based on their work interactions and activities are made via the course's Web environment. The fifth step of the ladder involves the systematic use and re-use of these workplace submissions by the other participants for peer review, reflection, and comparative activities, leading to better sharing and reuse of experiences across the company. A collaboration with researchers from the University of Twente based on an action-research methodology supports the evolution (Collis \& Joergensen, 2005). The action-research process has worked in a dynamic way, where the researchers have been active partners in the learning evolution. Since 2001, over 70 courses have been redesigned to reflect this work-based version of blended learning. In terms of the First Principles Plus reference model, the context-specific strategic principles which have emerged from the action-research process for the Shell EP context are:

- Collaboration not only among participants in a course but also with colleagues in the workplace.

- Knowledge sharing and learning from others - not only peers in the course, but also experts and colleagues in the workplace, coaches/mentors, and others elsewhere in the organization, through integrating in-house knowledge sharing networks within the courses.

- Involvement of the participants' supervisors, who are seen as the key stakeholders and workplace-learning partners

- $\quad$ Re-use of knowledge and learning materials/artefacts that already exist in the participants' workplaces and can be used to demonstrate prior experience.

- Differentiation, by building upon the professional differences (experience), regional differences in the workplace situations, and ethnic (cultural) diversity of the participants.

- Effective technology design, for the environments in the Web-based course-support system

For the course-scan process, clusters of items have been developed to reflect each of the 11 sets of entities in the reference model (five first principles and six strategic principles for the Shell EP context). Table 1 shows a typical example from each cluster. In the participant evaluation questionnaire, a subset of the same items appear, edited slightly in wording so that they relate to the learner's own experiences.

Table 1. Examples of course-scan items for each of the 11 First Principles Plus components for the Shell EP context

\begin{tabular}{|l|l|}
\hline First Principles Plus components & $\begin{array}{l}\text { Examples of course-scan items (each measured on a 5- } \\
\text { point scale, where 1=Not at all, and 5=Very much so }\end{array}$ \\
\hline $\begin{array}{l}\text { Generic 1: Anchoring in business } \\
\text { problem (Problem) }\end{array}$ & $\begin{array}{l}\text { To what extent do the activities in the course relate to the } \\
\text { participants' real workplace problems? }\end{array}$ \\
\hline $\begin{array}{l}\text { Generic 2: Activation of prior } \\
\text { knowledge and skills as a basis for } \\
\text { new knowledge and skills } \\
\text { (Activation) }\end{array}$ & $\begin{array}{l}\text { To what extent do the activities attempt to activate relevant } \\
\text { prior knowledge or experience? }\end{array}$ \\
\hline $\begin{array}{l}\text { Generic 3: Demonstration/examples } \\
\text { of what is to be learned } \\
\text { (Demonstration) }\end{array}$ & $\begin{array}{l}\text { To what extent are the learners shown examples in the } \\
\text { workplace of what is to be learned rather than merely told } \\
\text { information about what is to be learned? }\end{array}$ \\
\hline Generic 4: Application of new & To what extent do learners have an opportunity to directly \\
\hline
\end{tabular}




\begin{tabular}{|l|l|}
\hline knowledge and skills (Application) & $\begin{array}{l}\text { practice and apply their newly acquired knowledge or } \\
\text { skill? }\end{array}$ \\
\hline $\begin{array}{l}\text { Generic 5: Integration of new } \\
\text { knowledge and skills into learner's } \\
\text { daily work (Integration) }\end{array}$ & $\begin{array}{l}\text { To what extent are there techniques provided that } \\
\text { encourage learners to integrate/transfer the new knowledge } \\
\text { or skill into their everyday work? }\end{array}$ \\
\hline $\begin{array}{l}\text { Strategic 1: Opportunities for } \\
\text { learning from peers (Learning from } \\
\text { others) }\end{array}$ & $\begin{array}{l}\text { To what extent do the learning activities provide } \\
\text { opportunities for participants to learn from each other? }\end{array}$ \\
\hline $\begin{array}{l}\text { Strategic 2: Supervisor's } \\
\text { involvement (Supervisor) }\end{array}$ & $\begin{array}{l}\text { To what extent were supervisors of the participants } \\
\text { involved in the course? }\end{array}$ \\
\hline $\begin{array}{l}\text { Strategic 3: Flexibility for learners } \\
\text { with different learning needs and } \\
\text { preferences (Differentiation) }\end{array}$ & $\begin{array}{l}\text { To what extent are there activities that build upon the } \\
\text { participants' different backgrounds and experiences? }\end{array}$ \\
\hline $\begin{array}{l}\text { Strategic 4: Collaboration with peers } \\
\text { in the course and/or others in the } \\
\text { workplace (Collaboration) }\end{array}$ & $\begin{array}{l}\text { To what extent do the activities involve collaboration with } \\
\text { peers in the course? With others in the workplace? }\end{array}$ \\
\hline $\begin{array}{l}\text { Strategic 5: Re-use of learning } \\
\text { materials from the business and in- } \\
\text { house knowledge sharing networks, } \\
\text { re-use of learner's submissions (Re- } \\
\text { use) }\end{array}$ & $\begin{array}{l}\text { To what extent are the study resources re-used from the } \\
\text { business? } \\
\text { To what extent do the activities involve re-use of } \\
\text { participants' submissions? }\end{array}$ \\
\hline $\begin{array}{l}\text { Strategic 6: Use of the Web site } \\
\text { functionalities (Web-support design) }\end{array}$ & $\begin{array}{l}\text { To what extent is the course environment well organized? } \\
\text { To what extent is the Discussion area well structured? }\end{array}$ \\
\hline
\end{tabular}

The course scan has been carried out on over 70 courses by the research team; a shorter version of the process is now carried out by the instructors themselves at the end of a course. The participant evaluation takes place at the end of each course cycle, via a Web-based instrument with items to be answered on a 1-5 scale (with 5 always the most-positive response) and opportunities for openended reflections. In the next section we illustrate the use of the reference model to contribute to a multi-participant reflection on lessons learned from a set of 12 blended courses over a series of three years in one of the faculties of Shell EP learning involved since the start in the learning evolution.

\section{An Analysis of 12 Blended Courses in the Surface Faculty}

The Surface Faculty in Shell EP Learning \& Leadership Development organisation is the group of production engineers and other technical professionals involved in bringing hydrocarbons from the environment in which they are found (undersea or underground) to above-ground production facilities (rigs and processing plants). Many types of courses are involved, including Production Modelling, Production System Optimisation, and Production Technology. In addition, courses relating to the maintenance of production environments as well as safety and environment protection are important in the curriculum. Course leaders representing these disciplines in the Surface Faculty as well as a number of subject-matter experts contribute to courses. The course leaders are overall responsible for their courses and are leaders of a course team and therefore have varying amounts of actual teaching and facilitating duties when the course is running. The redesigned courses in the Surface team are good candidates for an investigation of the impact of the new form of learning design, from multiple perspectives and in terms of lessons learned for others. The following comments combine the data from the fourth quarter 2004, from multiple perspectives: the evaluation-questionnaire data from 130 respondents from 12 blended courses, combined with the perspectives of the six course leaders from those courses and the perspectives of the researchers/designers using the results of the course scans. The results are discussed around four major focuses: the impact of the courses on the business, the experience of the courses for those involved, overall impressions, and the lessons learned (Amory, 2005, for the course leaders' perspectives; Collis, 2005, and Margaryan, 2005a, for an overall synthesis of the participant 
evaluation data; and Margaryan, 2005a, for the researchers' perspective using a synthesis of the course-scan results for the 12 courses ). The course leaders' perspectives arose out of a series of reflective discussions in which the course leaders summarized their impressions of their blended courses and the lessons learned. For all participant and course-scan data, the scale is 1-5, with 1 lowest and 5 highest.

\section{Overall impressions}

The participants are very satisfied with the blended courses (mean=4.0, $\mathrm{sd}=0.5$ ). They indicated that the courses met their objectives (mean=4.1, $\mathrm{sd}=0.3$ ) and they also gave many positive openended comments, such as "I like the workshop setting, as opposed to 'show \& tell'. This has been one of the best courses I ever attended in Shell!" and "I very much liked being able to work on realistic problems as an integral part of the course, and doing so with some of my team mates from my real work environment". The course leaders are also unanimous in their overall conclusions: "A blend of delivery methods is required for efficient learning and advanced learning techniques are required. Our form of workplace learning provides faster, cheaper, and better learning; learning is immediately applied.... The approach encourages technical coaching in the workplace.

Everyone is engaged. Participants can work at their own pace. More dimensions of assessment are possible than before." The overall course-scan scores for the 12 courses mirror this positive reaction, as shown in Figure 2 (where the overall total score is comprised of the average score on the 11 components from the reference model on a 1-5 scale, thus with a total of 55 possible.

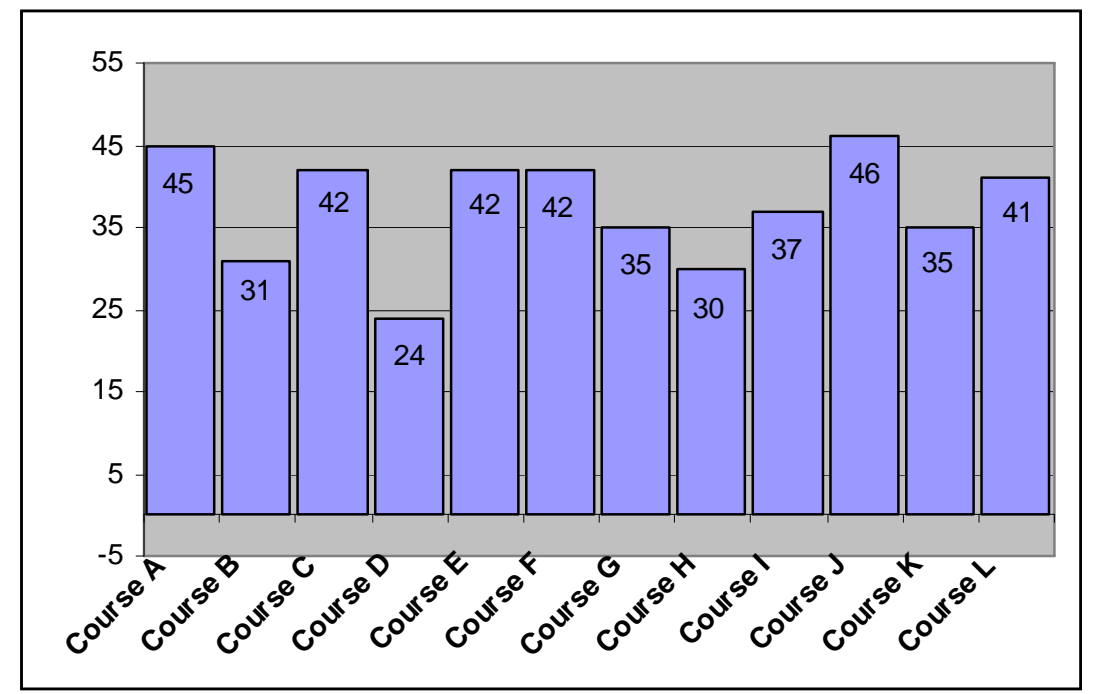

Figure 2. Course-scan scores on the 12 blended courses (maximum score $=55$ )

Thus, from each of the actors' perspectives, the approach to learning design is evolving well and being positively experienced. "Putting learning to work" as a learning-design theme is paying off in practice.

\section{Impact on the business}

From the course leaders' perspectives, the new learning design featuring blended learning with workplace assignments "works". The course leaders all agree that this form of learning design leads to courses with "high relevance to the business", through "identifying and solving immediate business problems", which leads to "more effective, deeper learning processes", and which also "promotes changes in work practices" and "promotes networking". An important aspect for this is that all courses are mapped about the company's "competence-based development building blocks" but also the work-based activities "allow the immediate application of the of theory to the reality of the workplace via learning and applying". From the researchers' perspective, the coursescan data support these observations of the course leaders. For the 12 courses, the overall mean 
score on the course scans for the variable "Anchoring in a business problem" was $4.0(\mathrm{sd}=1.1)$ and the overall mean score for the variable "Application of new knowledge and skills" was 4.4 $(\mathrm{sd}=0.5)$. In terms of the participant responses, the results were also positive in terms of key indicators of business impact, but not as strongly positive as the impressions of the course leaders and researchers/designers. On the key variable, "The course is likely to have an impact on the business and on my own workplace" the participants' mean score was $3.5(\mathrm{sd}=0.7)$. When all participant items were entered into a regression analysis to see which were the strongest predictors of this business-impact variable from the participants' perspective, the most significant predictor was "The course helps me to become a better professional" $\left(r^{2}=.159, F=11.29, p<.00\right)$. Thus, the participants feel that the more the course involves the strengthening of their professional behaviours (in contrast to the acquisition of content), the more likely it will be of benefit to the business and workplace situations. This conclusion can be supported by open-ended responses made by the participants, for example. "As a mixture of good theory, expertise and practical experience, this type of learning builds a proper structural system of approaches and business solutions", "Work place assignment were very good in practicing PT skills", "It was the fact that all pieces finally fell together. I understood the E \& P business", and "As a core member of a team employing RCM in my team, the sound knowledge of RCM acquired from this course has empowered me to be a key driver in the process".

\section{The experience of the course for those involved}

While the overall impact on the business is a critical outcome of corporate courses, the courses must also be perceived as positive in terms of the way in which their designs are experienced by those involved. In terms of the course leaders, the involvement of local senior technical people to support the participants during the work-based activities was seen as a key benefit of the courses in comparison to traditional classroom models. The participants were also pleased with the support and coaching they received at the workplace, from their supervisors (mean $=3.7, \mathrm{sd}=0.5)$ but also with the interactions they had with other "learning partners" in their workplaces (mean=3.8, $\mathrm{sd}=0.8$ ). The key to these workplace interactions is the design of the learning activities so that there are explicit steps involved that call for input and coaching from supervisors and others in the workplace. In the course scans, however, this explicit integration of supervisor engagement was not often seen in the instructions for the work-based activities, with a mean score of only 1.9 $(\mathrm{sd}=0.7)$ for the 12 courses. Apparently the participants and course leaders perceive a higher level of workplace involvement with supervisors and other coaches than what has been based by their learning-activity designs in the courses. What this perception is based on is the subject of a further line of research (Bianco, 2005).

While work-based activities were seen as valuable to all, there was also agreement between the course leaders and the participants that "finding the right balance between the workplace activities and the time required to complete them" (in the words of the course-leader summary) remains a challenge. The open-ended responses of the participants support this, for example, "Although the learning tasks really aligned with my job and therefore made this course very relevant, the blended learning style was difficult to balance with a busy job. I was often not able to put in the hours I wanted to". The participants however were highly positive about the activities (mean=4.0, $\mathrm{sd}=0.5$ ), regardless of the time involved, as demonstrated in the previous comment. They also appreciated the way the local strategic variables had been experienced in the courses, particularly peer interaction (mean=3.8, sd=0.6), the likelihood of sharing what was learned with others in the workplace (mean 4.2, sd=0.4), and the way the course Web environment was used to support their work-based learning (mean=4.0, $\mathrm{sd}=0.9$ ). However, the course-scan data reveals that in the researchers' perspectives, there is still progress to be made in the courses in terms of the key strategic variables as shown by the mean course-scan scores in Table 2. 
Table 2. Course-scan scores (means and standard deviations) on strategic variables, $\mathrm{n}=12$ Surface faculty blended courses (scoring on a range of $1-5$, with $1=$ little or none and $5=$ best-practice

\begin{tabular}{ll}
\multicolumn{2}{c}{ example) } \\
\hline Involving the supervisor & $1.9(0.7)$ \\
\hline Learning from others & $2.8(1.0)$ \\
\hline Differentiation to optimise differences among participants & $3.7(0.2)$ \\
\hline Collaboration & $3.7(1.7)$ \\
\hline Re-use of resources from the business or from other participants & $3.3(0.9)$ \\
\hline $\begin{array}{l}\text { Technology design (design and use of the course Web } \\
\text { environment) }\end{array}$ & $3.7(0.8)$ \\
\hline
\end{tabular}

\section{Lessons Learned}

There are a number of valuable lessons learned from three years of experience with the dynamic evolution of these 12 blended courses. The following guidelines reflect some of the key points made by the course leaders, the researchers, and the participants that will be of direct benefit to other course leaders at Shell EP and are being applied directly by the Surface faculty in their upcoming courses.

\section{Guidelines from the course leaders:}

- Focus on the competence blocks that matter most. Don't try to cover too much in one course.

- Make sure that the assessment structure is transparent, clearly defined, and communicated to all upfront. Look for a balance of types of assessment, particularly of assessment of the workbased activities

- Get the technical coaches involved in the workplace activities.

- Embed coaching in the planning for the activities. Coaches need to be identified well upfront by the participants and/or the organization.

- Be critical about the actual time spent on courses while in the workplace. The acceptable seems to be between four and eight hours per week. Ensure that the supervisor makes enough time available.

- Don't underestimate the resources needed to operate this new type of course.

- Provide references to both internal and external references. Indicate if a reference is a "must, should or could" read. Be critical about overloading with too much material.

- Capture business-value examples from the participants' submissions during the course.

\section{Guidelines from the researchers:}

- In addition to activities where collaboration with experts/experienced colleagues in the learners' own workplaces is required, include more collaborative activities among the learners themselves.

- Design activities where participants can analyse each other's work, in addition to sharing their experiences. For example, they can do peer review and peer-assist activities based on the submissions. This will increase knowledge sharing and the opportunity from each other's different backgrounds.

- Structure more-specific activities for the involvement of coaches and supervisors via workbased activities.

- Integrate the use of the community-of-practice resources supported by the knowledgemanagement team in Shell EP; blend more use of informal learning resources from the business into the courses.

Guidelines from the participants:

- Improve the facilitation of discussions, both those carried out via TeleTOP and in the classroom

- Manage time realistically and balance with workplace demands 
- Strengthen interaction between the participants, particularly in course components carried out at a distance

Guidelines from all the perspectives combined:

- Continue to carry out the action-research approach.

- Continue to evolve the blended approach with workplace activities.

- Pay particular attention to the balance between time available and expectations in the workplace portions of the course

- Have regular reviews of the strategic entities in the reference model, to adapt them, to share best practices, or to focus on entities for strengthening in practice.

\section{Conclusion}

The approach to learning design that has evolved at Shell EP is the result of dynamic action research over more than four years of a productive partnership between Shell EP Learning and Leadership Development and researchers from the University of Twente. Innovative new practices have emerged, grounded in research, and emphasizing active, collaborative, authentic, and engaging learning experiences. The key is blended learning, where a substantial amount of the learning takes place in the workplace, not through self-study of e-modules but rather through work-based activities that involve others in the workplace as learning partners and also make use of resources from the business that in many cases are found or developed by the participants themselves. This form of participant engagement reflects all five components of Merrill's "first principles of instruction" (2002), tailored to the corporate setting. The addition of local strategic variables to fit the particular corporate context and culture is an important part of the approach. These will be different in each different corporate context, depending on the strategic goals of the company. In the Shell EP case, knowledge sharing among technical professionals from many different backgrounds is an important strategic tool for responding to the mobility of personnel within the company, as seniors, primarily from Western countries gradually retire and new technical professionals, primarily from non-Western countries, take their places. Thus many of the strategic goals for the Shell EP setting emphasize learning from others and from resources and experiences in the company. The use of the reference model provides an integrative framework for a variety of important activities such as design, evaluation, reflection, articulation of lessons learned, and strategic thinking about the total learning experience.

\section{References}

Amory, M. (2005). Blended learning experience: Surface faculty. Internal report, Shell EP Learning and Leadership Development, Noordwijkerhout, The Netherlands.

Bianco, M. (2005). Involving the supervisor in work-based blended learning. $\mathrm{PhD}$ dissertation, in progress (to be submitted in third-quarter 2005). Faculty of Behavioural Science, University of Twente, Enschede, The Netherlands

Collis, B. (2005). Analysis of participant course evaluation data, 84 course cycles, 2004. Internal report, Shell EP Learning and Leadership Development, Noordwijkerhout, The Netherlands.

Collis, B., \& Joergensen, E. (2005, 6 June). Partners in a learning evolution. Paper presented at the ASTD International Conference and Exhibition, Orlando, FL.

Collis, B., \& Margaryan, A. (2005). Merrill plus: Blending corporate strategy and instructional design. Educational Technology, 45(5), 54-58.

Goodrum, D. A., Dorsey, L. T., \& Schwen, T. M. (1993). Defining and building an enriched learning and information environment. Educational Technology, 33(11), 10-20.

Margaryan, A. (2005a). Course-scan results of the Surface Faculty's blended courses. Internal report, Shell EP Learning and Leadership Development, Noordwijkerhout, The Netherlands. 
Margaryan, A. (2005b). Work-based learning for technical professionals: A blend of pedagogy and technology. PhD dissertation, in progress (to be submitted in third-quarter 2005). Faculty of Behavioural Sciences, University of Twente, Enschede, The Netherlands.

Margaryan, A., \& Collis, B. (2004, 27 November). Designing technology-supported work-based learning for professional competence development. Paper presented at the International Conference for Professional Learning in a Changing Society, Institute for Educational Research, University of Oslo, Oslo, Norway.

Merrill, D. (2002). First principles of instruction. Educational Technology Research and Development, 50(3), 43-59.

Raelin, J. (1998). Work-based learning in practice. Journal of Workplace Learning, 10(6/7), 280283.

South Florida Center for Educational Leaders (FSCEL), (2005). How is action research defined? Accessed 30 April 2005 from http://www.coe.fau.edu/sfcel/define.htm .

(C) Copyright Betty Collis, Anoush Margaryan, Marc Amory [2005].

Please cite as: Collis, B., Margaryan, A., Amory, A. (2005). Multiple perspectives on blended learning design. Journal of Learning Design, 1(1), 12-21. www.jld.qut.edu.au/Vol 1 No 1 